\title{
EDUCAÇÃO, TRABALHO E NOVAS TECNOLOGIAS NA EDUCAÇÃO A DISTÂNCIA: UMA REFLEX ̃̃O CRÍTICA
}

\section{RESUMO}

\author{
Raquel de Almeida Moraes ${ }^{\mathrm{i}}$
}

O artigo objetiva refletir sobre a relação educação, trabalho e novas tecnologias na educação a distância a partir da abordagem materialista histórico-dialético. Questiona que na sociedade capitalista a formação humana é voltada para atender aos interesses de formação da classe dominante e que na fase atual, onde predomina o capitalismo flexível e informacional, as novas tecnologias na educação a distância levam à alienação e à precarização do trabalho docente.

Palavras- chave: Educação; Trabalho; Novas Tecnologias; Educação a Distância.

\section{EDUCATION, LABOR AND NEW TECHNOLOGIES IN DISTANCE EDUCATION: A CRITICAL REFLECTION}

\begin{abstract}
This article reflects on the relationship between education, labor and new technologies in distance education from the historical and dialectical materialist approach. Asks that in capitalist society the human development is geared to meet the training interests of the ruling class and that in the current phase, dominated by the flexible and informational capitalism, the new technologies in distance education lead to alienation and the precarization of work teaching.
\end{abstract}

Keywords: Education; Labor; New Technologies; Distance Education.

\section{DELIMITANDO O CAMPO}

O debate em torno dos paradigmas ou modelos teóricos da relação entre Educação e Tecnologia é oriundo da Economia e Sociologia industrial e tem influenciado, segundo Maria Luisa Belloni (1999, p.9), "não apenas a elaboração dos modelos teóricos, mas as próprias políticas e práticas de EaD”.

Para Lacerda Santos e Moraes (2003, p. 11)

A educação tem um papel crucial na chamada "sociedade tecnológica". De fato, é unicamente por meio da educação que teremos condições, enquanto indivíduos, de compreender e de se situar na sociedade contemporânea, enquanto cidadãos coparticipes e responsáveis.

Originária do termo alemão Bildung - que significa a formação do indivíduo - em Economia e Sociologia Industrial essa palavra, para Frigotto (1992) é sinônimo de Qualificação do Trabalhador.

Em Marx, o conceito de qualificação implica em concebê-la como "um conjunto de condições físicas e mentais que compõem a capacidade de trabalho ou a força de trabalho 
dispendida em atividades voltadas para a produção de valores de uso em geral" (FRIGOTTO, 1992, p.9).

Essas condições físicas e mentais representam a síntese de elementos tais como: grau médio de destreza dos indivíduos; disponibilidade de recursos naturais; organização social da produção; quantidade e qualidade dos meios para produzir.

Em relação às novas tecnologias, Frigotto (1992, 1995), Hirata (1994), Saviani (1994), Belloni (1999), entre outros, argumentam que essas tecnologias têm demandado novas competências dos trabalhadores. Dessa forma, a Educação tem sido desafiada a se posicionar, tanto teórica quanto praticamente.

E por que isso ocorre? Vejamos.

Segundo Hirata (1994), a produção no regime de acumulação fordista baseia-se na fabricação em massa de bens padronizados mediante o uso de máquinas especializadas não flexíveis e com trabalhadores semiqualificados.

A esses trabalhadores se exige um cumprimento rigoroso das normas operatórias, segundo um best way, com prescrição das tarefas e disciplina no seu cumprimento, a não comunicação (isolamento, proibição de diálogos durante o trabalho em linha etc.) (HIRATA, 1994, p. 129).

Já o modelo da organização flexível é resultante das inovações tecnológicas, da descentralização e da abertura ao mercado internacional no contexto da globalização. Essa flexibilidade levaria ao retorno de um tipo de trabalho artesanal, qualificado e em cooperação entre management e funcionários multifuncionais (HIRATA, 1994).

Para Hirata (1994), o modelo da competência, oposto ao da qualificação, implica um compromisso pós-taylorista, onde os trabalhadores são levados no novo modo de organização do trabalho "a uma participação na gestão da produção, a um trabalho em equipe e a um envolvimento maior nas estratégias de competitividade da empresa, sem ter necessariamente uma compensação em termos salariais" (idem, p.133). Já a qualificação estaria diretamente relacionada ao momento fordista, onde para cada tarefa se requer uma especialização.

A autora coloca, então, o eixo da problemática da competência centrado nas categorias trabalho e linguagem argumentando, com PH Zarifan, de que é necessário fazer uma nova síntese entre esses dois conceitos, como o trabalho comunicacional, a propósito da assertiva de Habermas e Claus Off de que o trabalho não teria mais centralidade nessa fase do capitalismo.

No entanto, para Frigotto (1995) tanto Habermas como Offe desconsideram a dimensão ontológica do trabalho que, em Marx, constitui a essência humana, pois é pelo trabalho, pela produção da vida material, que o homem se constitui como sujeito histórico.

Para Marx (2008) "O modo de produção da vida material condiciona o processo de vida social, política e intelectual. Não é a consciência dos homens que determina seu ser; é o seu ser social que determina sua consciência" (MARX, 2008, p. 47)

Ademais, Frigotto (1995) ressalta a fragilidade de argumentação empírica de Offe pois a Europa, longe de abdicar da centralidade do trabalho estrutura "uma verdadeira cortina de ferro para proteger postos de trabalho" (idem,p. 114) contra os desempregados do Terceiro Mundo.

Para Antunes (1995), o toyotismo caracteriza-se pelo trabalho cooperativo, em equipe, onde a falta de demarcação de tarefas demanda uma qualificação polivalente e 
multifuncional. No entanto, a produção flexível, típica do Estado neoliberal, exige conhecimentos e atitudes diferentes das qualificações requeridas pelas organizações fordistas (americanas) e toyotistas (japonesas), pois estas ainda são fragmentadas e controladas. Assim, o trabalhador pós-fordista, de acordo com sua análise e da qual concordamos, ainda encontra-se alienado.

Com a crise do fordismo nos países capitalistas centrais e o processo de produção nos países que não conheceram o well/warfare state, surgem novos processos de produção industrial (pós-fordismo e toyotismo), os quais passam a influenciar tanto a concepção como a gestão do trabalho e todas as dimensões sociais a ele relacionadas. Ligado à lógica "pós-moderna" e pós-fordista, esses novos processos, em geral, enfatizam o aprender ao longo da vida, a educação para o pensar e o trabalho em redes, ao contrário da lógica taylorista/fordista de produção em massa da linha de montagem, onde se tinha uma clara e nítida divisão do trabalho: os pensadores e os executores que correspondem aos trabalhadores intelectuais e os manuais respectivamente.

Se em educação, o fordismo e o tayolorismo correspondem ao behaviourismo (BELLONI, 1999), o pós-fordismo está relacionado com a crítica ao industrialismo instrucional e propõe o diálogo entre professores e alunos, em situação como: aprendizagem aberta, aprendizagem flexível, fleximodo, campus aberto ou campus virtual.

Segundo Belloni (1999, p.14-15), há dois modelos de Educação a Distância - EaD. O primeiro deles está ligado ao modelo taylorista-fordista de educação, onde a EaD é entendida como um processo industrial de trabalho. Nessa perspectiva, sua estrutura é determinada pelos seguintes princípios: racionalização, divisão do trabalho e produção em massa, acrescido de crescente mecanização e automação. Essa lógica de "massa" vai evidenciar-se na oferta da educação (universalização do ensino fundamental e depois o secundário) e nas estratégias (grandes unidades, planejamento centralizado, otimização de recursos, etc.).

$\mathrm{Na}$ educação, essa lógica de "massa" evidencia-se, segundo Belloni (1999) na expansão da oferta de educação (inicialmente para o nível fundamental e posteriormente o médio) e nas estratégias implementadas: grandes unidades, planejamento centralizado, otimização dos recursos, uso de tecnologias.

Aplicada à organização de sistemas de $\mathrm{EaD}$, as estratégias fordistas sugerem a existência de um provedor centralizado, de âmbito nacional, fazendo economia de escala, o que implica um controle administrativo e uma divisão de trabalho intensa. Na comunicação em $\mathrm{EaD}$, a ênfase está na produção e no material produzido.

Já o modelo pós-fordista, segundo Blandin (1990, cf. BELLONI, 1999, p.87), sinaliza algumas competências necessárias aos profissionais da educação que deverão desenvolver competências em quatro grandes áreas: 1) Cultura técnica - em audiovisual e informática ; 2) Competência da comunicação; 3) Capacidade de trabalhar com método; 4) Capacidade de capitalizar seus saberes e experiências.

Para Saviani (2007) a "pedagogia do aprender a aprender", tem o "objetivo de dotar os indivíduos de comportamentos flexíveis que lhes permitam ajustar-se às condições de uma sociedade em que as próprias necessidades de sobrevivência não estão garantidas" (idem, p. 435).

Transferida a responsabilidade dos empregos pelo Estado de bem-estar social para os próprios indivíduos sob o Estado Mínimo, Saviani conclui que essas transferências os tornam subjugados à "mão invisível do mercado". 
Já as empresas mudam a qualificação pela competência e, nas escolas, procura passar "do conhecimento das disciplinas de conhecimento para o ensino de competências referidas às situações determinadas." (SAVIANI, 2007, p. 436). E a partir de Marx teoriza que ser produtivo não significa apenas produzir mais mercadorias mas "criar valor de troca, isto é, mais-valia" (idem, ibidem).

Assim, para Saviani, desde os anos 1990 que nós não conseguimos escapar do neotecnicismo, que se faz presente alimentando a busca da qualidade total na educação e com a penetração da pedagogia corporativa.

Apesar de Belloni (1999) teorizar que são dois os Modelos de EAD, fordista e pósfordista, propomos a inclusão de um terceiro Modelo teórico para a análise da relação Educação e Trabalho, que é o modelo da Politecnia ou da Educação Omnilateral, tal como pensado pela concepção marxista de Educação por esta teoria fazer parte do cabedal teórico da educação na perspectiva contra-hegemônica.

Nessa perspectiva, tem-se como pressuposto o processo de construção de uma outra sociedade, onde o trabalho é concebido como um princípio educativo. Sobre as novas tecnologias, Saviani (1994) argumenta que o que estamos vivendo na atualidade é a transferência das funções intelectuais para as máquinas (autômatos), colocando como desafio a necessidade de uma maior qualificação da classe trabalhadora dado que suas funções intelectuais estão sendo absorvidas pelos autômatos.

Para Frigotto (1992, p.48-49), a politecnia implica na superação da fragmentação, utilitarismo e na unidade teoria e prática. Exige uma nova função social da escola, isso porque o saber politécnico se situa na perspectiva do desenvolvimento de todas as qualidades humanas no processo de superação das relações sociais de alienação e de exclusão.

A seu ver a "alternativa da educação numa perspectiva socialista democrática não pode inventar uma realidade supra-histórica. Ela se gesta no embate contra-hegemônico de dentro desta materialidade" (FRIGOTTO, 1995, p. 203).

A qualificação demandada nessa nova etapa, para Saviani (1994, p.164), requer “a universalização da escola unitária que desenvolva ao máximo as potencialidades do indivíduo (formação omnilateral), conduzindo-os ao desabrochar pleno de suas faculdades espirituais-intelectuais", em oposição ao mercado capitalista global.

Nosella (2007, p.149) considera que

[...] todo cidadão precisa comunicar-se com propriedade, produzir algo para si e para outros [...] "Nesse sentido, a escola não pode renunciar à disciplina de estudo e à precisão científica e cultural, mas precisa também possibilitar aos jovens", segundo Manacorda, "um espaço em que cada um livremente se forme naquilo que é de seu gosto".

Sobre a problemática da Educação e Trabalho, Lacerda \& Moraes (2003) alertam que a análise de diferentes estudos sobre esta temática sugere que qualquer que seja a configuração futura da sociedade, a intervenção do indivíduo enquanto cidadão participativo e determinante em seu meio social continuará dependendo de sua posição no sistema produtivo. Para eles, não há nenhum indício de que a sociedade tecnológica emergente será mais justa, mais prazerosa, mais democrática, mais igualitária.

O avanço tecnológico e suas implicações sobre o modo de funcionamento do mercado de trabalho estariam conduzindo, segundo Antunes (1995), a sociedade a uma 
intensificação da exploração do trabalhador, favorecendo a proliferação do trabalho terceirizado, parcial e precário, sem direitos e sub-remunerados, fortalecendo o mercado dual de trabalho.

Para os teóricos críticos, o discurso que advoga uma crescente qualificação da força de trabalho é um mito que faz parte e apoia a manutenção de um modelo de produção que preserva, em sua totalidade, o fetichismo da mercadoria e a alienação.

Saviani (2005) destaca que a alienação está presente no trabalho material dado que o produto do trabalho se separa do trabalhador. Sobre o trabalho não material, Saviani teoriza a existência de dois tipos, sendo que o primeiro consiste em que o produto se separa do produtor, dando como exemplo a produção de livros. No segundo, em que o produto não se separa do trabalhador, ele dá como exemplo o professor. Relacionando a educação ao trabalho educativo, Saviani afirma se educação não se resume ao ensino, "é certo, entretanto, que ensino é educação". (SAVIANI, 2005, p. 12.)

Saviani é claro ao demandar uma formação tecnológica do tipo politécnica, não alienante, que explicite o caráter não humano das tecnologias salientando a necessidade de explicitar os princípios científicos e tecnológicos que as originam.

Para ele, as tecnologias são meios e não podem ser fetichizados sob o risco de que o trabalho do professor, não material, seja alienado, como ocorre nos cursos à distância tal como praticado na atualidade.

Barreto (2010) questiona esse vínculo entre novas tecnologias, sua congênere tecnologias da informação e comunicação, TIC e demandas por educação argumentando com Bernstein e Fairclough (cf. Barreto, 2010, p. 34) de que há um duplo movimento: estrutura e escala. Na estrutura há deslocamento conceitual do campo social de origem (empresa) para a educação no sentido de sua mercantilização. Na escala esse deslocamento segue as orientações dos organismos internacionais.

A autora argumenta que em se tratando de formação de professores esses movimentos são fundamentais, tal como se pode depreender do Documento S/CSS/W/23, de 18 de dezembro de 2000, da Organização Mundial do Comércio (World Trade Organization - WTO, 2000, p. 1), cuja proposta é, segundo tradução livre da autora

[...] liberalizar a comercialização deste importante setor da economia mundial, removendo obstáculos que se opõem à transmissão desses serviços além da fronteiras nacionais por meios eletrônicos (e-educação) ou pelo estabelecimento e exploração de instalações (como escolas) para proporcionar serviços a estudantes em seu país ou no estrangeiro. (BARRETO, 2010, p.34)

Já para Feenberg (2010, p. 167), as "tecnologias não são apenas meios que conduzem aos fins; elas dão forma também a mundos". E pergunta: "Que tipo do mundo é instituído pela internet?" Ao fazer isso, critica o modelo por ele denominado de Fábrica, que consiste em máquinas automatizadas de ensinar ou em cópias pobres de salas de aula presenciais em contraposição ao modelo da Cidade que tem com o desafio utilizar as redes eletrônicas de modo a que sejam apropriadas por instituições educacionais de forma dialógica.

A nosso ver, a emancipação, ideal perseguido desde o Iluminismo, requer cidadãos conscientes e autônomos. A educação, desde uma perspectiva histórico-crítica, tem por fim 
estimular essa formação. E para isso, há que transformar o risco em desafio, o veneno em vacina, a dominação em dialogia (MORAES, 2010).

\section{CONSIDERAÇÕES FINAIS}

Conforme argumentam Lacerda Santos e Moraes (2014), no capitalismo em crise, a produção e a posse do conhecimento torna-se fator determinante no grande tabuleiro de xadrez mundial. Marxistas e pós-modernos disputam sua apropriação e difusão. Enquanto os pós-modernos como Lyotard (1989) defendem que a ciência é feita por dissensos, é um jogo de linguagem onde vence o mais capaz de produzir algo rentável, competitivo e protegido por patentes, os marxistas argumentam que o conhecimento é intrinsecamente não apropriável pois tem por base o trabalho social.

De acordo com Mattelart (2002) a referência ao termo "Sociedade da Informação" aparece sub-repticiamente nos organismos multilaterais, internacionais, após a década de 1970. Em 1975 a Organização de Cooperação e de Desenvolvimento para o Comércio (OCDE), estreia a noção e em 1979 usa o termo como palavra chave em programa experimental: Forecasting and Assessment in the Field of Science and Technology, FAST, que inicia oficialmente em 1980.

No campo das ideias, esses organismos, incluindo o Banco Mundial, aderem ao debate do lado dos pós-industriais e pós-modernos. Entre as evidências se encontra o documento publicado em 2003: Lifelong Learning in the Global Knowledge Economy. Em português: Aprendizagem Permanente na Economia Global do Conhecimento. (BANCO MUNDIAL; WORLD BANK, 2003)

O Banco Mundial desenvolveu uma Metodologia de Avaliação do Conhecimento (KAM), por meio da qual se elaboram os Índices da Economia do Conhecimento (KEI) (BANCO MUNDIAL; WORLD BANK, 2012). O KAM consiste em 81 variáveis estruturais quantitativas e qualitativas para 132 países, que servem para avaliar sua performance nos 4 pilares da Economia da Informação, a saber: 1) incentivos econômicos e regime institucional, 2) educação, 3) inovação e 4) tecnologias da informação e comunicação. As variáveis são normalizadas em uma escala de 0 a 10, relativas aos outros países no grupo de comparação.

Abaixo temos o gráfico produzido pelo Banco Mundial que traduz essas variáveis no planeta:

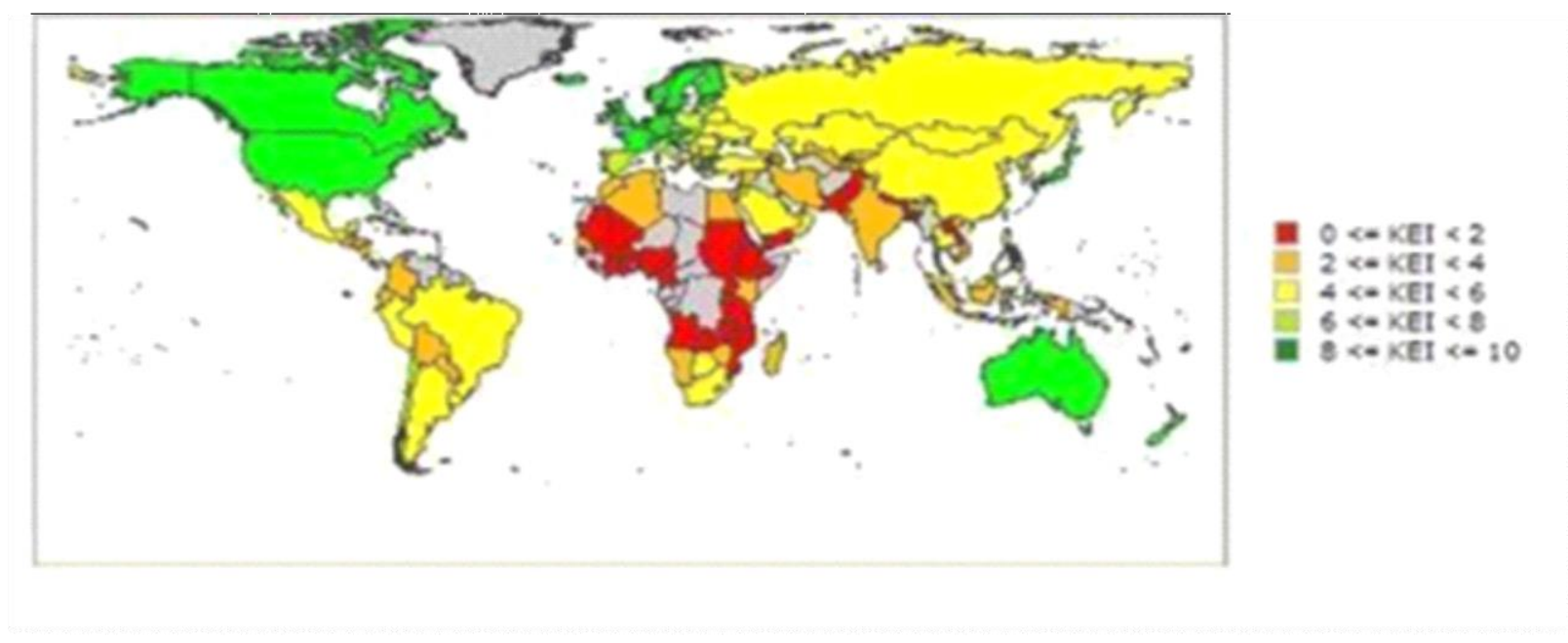

Fonte, Banco Mundial, 2007.

Revista HISTEDBR On-line, Campinas, $n^{\circ}$ 65, p.103-112, out/2015 - ISSN: 1676-2584 108 
O conhecimento produzido, no entanto, se transforma em propriedade intelectual. Para Dupas (2007) a propriedade intelectual, PI regulada por meio de um rígido controle da utilização de marcas e patentes, é um dos pilares do sistema de acumulação capitalista global.

Esse rígido controle da PI utiliza-se intensamente das instituições internacionais como Organização Mundial do Comércio (OMC), Banco Mundial (BM) e Fundo Monetário Internacional (FMI), mas, paradoxalmente, começa o questionamento sobre o peso dos custos envolvidos em ações defensivas dessas grandes corporações. Para Dupas (2007) a propriedade industrial regulada por meio de um rígido controle da utilização de marcas e patentes, é um dos pilares do sistema de acumulação capitalista global.

De acordo com Brzezinski (1996), a supremacia americana que se estabeleceu no mundo após 1991, produziu uma nova ordem mundial que não só duplicou, mas institucionalizou muitas das características do sistema que inclui:

1) Sistema coletivo de segurança internacional (NATO, USJapão etc.);

2) Cooperação econômica regional (APEC, NAFTA) e institucional (Banco Mundial, FMI, Acordo do Comércio Mundial;

3) Procedimentos que enfatizam o processo decisório de modo consensual;

4) a preferência pela democracia dentro das alianças;

5) Constituição global e estrutura judicial (Corte de Haia - crimes da Bosnia)

No entanto, isso acarreta o cesso desigual ao conhecimento científico. Para Annan (2003, p. 1485, apud Tilly, 2006, p.48):

Se considerarmos o acesso ao conhecimento científico benéfico uma forma de liberdade, então a reserva desse conhecimento limita a liberdade no mundo" "cerca de $95 \%$ da nova ciência é criada nos países que abrigam somente um quinto da população mundial. Grande parte dessa ciência - no âmbito da saúde, por exemplo - negligencia os problemas que afligem a maioria da população mundial. A distribuição desigual da atividade científica gera sérios problemas não só para a comunidade científica dos países em desenvolvimento, mas para o próprio desenvolvimento. Ela acelera a disparidade entre países avançados e em desenvolvimento, criando dificuldades sociais e econômicas no plano nacional e internacional. A idéia de dois mundos científicos é um anátema ao espírito científico. A mudança desse cenário e a extensão dos benefícios da ciência a todos exigirão o empenho dos cientistas e das instituições científicas em todo o mundo

Informação, patente, dominação, acumulação. Para Mattelart (2002) foi sobre a sombra da tese dos fins, começando com a do fim da ideologia, que foi incubada, ao longo da Guerra Fria, a idéia de sociedade da informação como alternativa aos dois sistemas antagônicos.

Contraposta a essa concepção, Raymod Williams (2011) teoriza que os meios de comunicação são meios de produção e estão diretamente subordinados ao desenvolvimento histórico. 
[...] das formas físicas mais simples da linguagem às formas mais avançadas da tecnologia da comunicação, são sempre social e materialmente produzidos e obviamente reproduzidos (p. 69).

A partir de uma perspectiva socialista, do uso comunitário democrático, seria possível alcançar "de modo razoável e prático, o sentido dado por Marx ao comunismo como a produção da forma mesma de comunicação", na qual, com o término da divisão do trabalho dentro dos próprios meios de produção e de comunicação, os indivíduos falariam "como indivíduos", como seres humanos integrais (p.78).

Em vista disso, pensamos que

\begin{abstract}
A tecnologia é fruto do trabalho humano, nela está contida a síntese do trabalho objetivado transposto para as máquinas. A tecnologia não é outra coisa senão trabalho intelectual materializado dando visibilidade ao processo de conversão da ciência, potência espiritual, em potência material, traduzida e protegida por patentes e direitos autorais que têm mantido, como salientado por Saviani, Dupas e Mèzsáros, a hegemonia da classe social que detém o Capital na sociedade (MORAES, 2010, p. 324)
\end{abstract}

A produção do conhecimento, portanto, não é neutra. Envolve o dispêndio de um trabalho situado no tempo e no espaço onde seus produtores ocupam uma posição de classe. A política tem assinalado, contudo, o benefício daqueles que detém o poder econômico e geopolítico.

Saviani (2007) tem razão quando postula que "o dominado não se liberta se ele não vier a dominar aquilo que os dominantes dominam. Então, dominar o que os dominantes dominam é condição de libertação" (Saviani, 2007, p. 55).

Finalizamos com alguns questionamentos sobre a atual política educacional de educação a distância:

Quais são os sentidos que a relação educação e tecnologia têm nos programas ministeriais? A presença das tecnologias é para mediar ou para aligeirar, tornando mais rápida a formação e precarizando o trabalho docente dos envolvidos (professores e tutores)?

A formação, por sua vez, é no sentido do desabrochar das "forças essenciais humanas", tal como posto por Marx, ou à fragmentação, dividindo o ser humano em competências e habilidades genéricas para um trabalhador polivalente, demandado pelo capital, ora flexibilizado e informacional?

\title{
Referências
}

ANTUNES, R. Adeus ao Trabalho? Ensaio sobre as metamorfoses e a centralidade do mundo do trabalho. São Paulo, Cortez, 1995.

BANCO MUNDIAL. Lifelong Learning in the Global Knowledge Economy. $<$ http://siteresources.worldbank.org/INTLL/Resources/Lifelong-Learning Learning-in-theGlobal-Knowledge-Economy/frontmatter.pdf> Acesso em 31/05/2013. 
BANCO MUNDIAL. Knowledge Assessment Methodology, KAM. 12 Disponível, 2007. em:

<http://web.worldbank.org/WBSITE/EXTERNAL/WBI/WBIPROGRAMS/KFDLP/EXTU NIKAM/0,,menuPK:1414738 pagePK:64168427 piPK:64168435 theSitePK:1414721,00 .html> Acesso em 21/12/12.

BARRETO, R. G. Configuração da política nacional de formação de professores a distância. Em Aberto, Brasília, v. 23, n. 84, p. 33-45, nov. 2010.

BELLONI, M. L. Educação a Distância. Campinas:Autores Associados, 1999.

BRZEZINSKI. Z. The Grand Chessboard: American Primacy and Its Geostrategic Imperatives. New York, NY: BasicBooks, 1997.

DUPAS.G. Propriedade Intelectual: tensões entre a lógica do capital e os interesses sociais. In: VILLARES, F. (Org.). Propriedade Intelectual: tensões entre a lógica do capital e os interesses sociais. São Paulo: Paz e Terra, 2007, p.15-24. Disponível em $<$ http://fido.rockymedia.net/anthro/dupas.pdf>Acesso em 21/2/12.

FEENBERG, A.A fábrica ou a cidade: qual o modelo de educação a distância via web? In: R. Neder (Org.). A teoria crítica de Andrew Feenberg: racionalização democrática, poder e tecnologia. Brasília: Observatório do Movimento Social na América Latina/CDS/UnB/Capes, 2010, p. 182-199.

FERRETI, C. et. Al. (Org.) Novas Tecnologias, Trabalho e Educação. Petrópolis:Vozes, 1994.

FRIGOTTO, G. et Al. Trabalho e Educação. Campinas: Papirus; Cedes; São Paulo: Ande; Anped, 1992.

Educação e a Crise do Capitalismo Real. São Paulo: Cortez, 1995.

LACERDA SANTOS; G; MORAES; R. A. A educação na sociedade tecnológica. In: LACERDA SANTOS, G. (Org.). Tecnologias na educação e formação de professores. 1ed.Brasilia: Editora Plano, 2003, v. 1, p. 11-30.

A Educação na Sociedade Informacional: anotações provenientes de uma pesquisa de natureza filosófica. Filosofia e Educação, v. 6, p. 266-288, 2014.

LYOTARD, J.F. A Condição Pós - Moderna. São Paulo: Loyola, 1989.

HIRATA, H. Polarização das qualificações ao modelo da competência.In: FERRETI, Celso et. Al. (Org.) Novas Tecnologias, Trabalho e Educação. Petrópolis:Vozes, 1994.

MATTELART, A. História da Sociedade da Informação. São Paulo: Loyola, 2002.

MARX, K. Contribuição para a crítica da economia política. São Paulo: Expressão Popular, 2008.

MORAES, R.A. Institucionalização da EaD nas IES públicas: uma perspectiva histórico crítica e emancipadora. In: Daniel Mill; Nara Pimentel. (Org.) Educação a Distância: desafios contemporâneos . 1 ed. São Carlos: EdUFSCar, 2010, v. 1, p. 319 -349.

NOSELLA, P. Trabalho e Perspectivas de formação dos trabalhadores: para além da formação politécnica. Revista Brasileira de Educação, v. 12, p. 137-151, 2007.

SAVIANI, D. O trabalho como princípio educativo frente às novas tecnologias. In: FERRETI, C, et. Al. (Orgs.) Novas Tecnologias, Trabalho e Educação. Petrópolis:Vozes, 1994, p. 147-164. 

2007.

TILLY, C. O acesso desigual ao conhecimento científico. Tradução de Alexandre Massella. Tempo Social, revista de sociologia da USP, v. 18, n. 2, p. 47-63, novembro 2006.

WILLIANS, R. Cultura e Materialismo. São Paulo: Editora Unesp, 2011.

WORLD TRADE ORGANIZTION (WTO). Council for Trade in Services Special Session. Communication from the United States: higher (tertiary) education, adult education and training. 2000. (S/CSS/W/23, 18 Dec. 2000). Disponível em: <www.unesco.org/ education/studyingabroad/highlights/global_forum/gats_he/us.pdf>. Acesso em 31/05/2012

\footnotetext{
${ }^{\text {i }}$ Professora Associada da Faculdade de Educação da Universidade de Brasília. Graduada em Pedagogia pela Universidade Estadual de Campinas (1985), mestre e doutora em Educação pela Universidade Estadual de Campinas (1996) e pós-doutorado em Filosofia da Educação pela Universidade de Haifa (2004). E-mail: rachel@unb.br.
}

Recebido: mai/2015 Aprovado: jun/2015 